\title{
Whether the School Self-Developed e-Learning Platform is More Conducive to Learning during the COVID-19 Pandemic?
}

\author{
Daxiang Dai, ${ }^{1}$ Xuyue $\mathrm{Xia}^{2}$ \\ 1. Tangquan Middle School, Nanjing 210000, Jiangsu, China \\ 2. Nantong University, Nantong 226000, Jiangsu, China
}

\begin{abstract}
The school self-developed e-learning platform can provide students with real and non-real-time learning resources based on its personalized learning properties like self-owned teaching conditions and levels. Meanwhile, it is beneficial to students' independent study and academic performance. During the COVID-19 pandemic, schools in China adopted e-learning platforms to conduct online teaching, whereas the efficacy of these online teaching platforms was not definitely known. It is necessary to review their effectiveness, especially for those developed by schools themselves. A total of 417 of 7 th and 8th graders from two middle schools in Nanjing, Jiangsu Province were enrolled with 208 in the experimental group and 209 as the comparisons. The primary outcome of the study was students' academic performance. The results demonstrated that: (i) the online platform-based self-learning was conducive to students' grades; (ii) school self-developed e-learning platform was more effective in improving student achievement than other nonschool self-developed ones.
\end{abstract}

Best Evid Chin Edu 2020; 5(1):569-580.

Doi: 10.15354/bece.20.ar030.

Keywords: COVID-19; E-learning Platform; Learning Effect; Middle School

About the Author: Daxiang Dai, Advanced Teacher, Tangquan Middle School, Nanjing 210000, Jiangsu, China. Email:447604856@qq.com;

Correspondence to: Xuyue Xia, Master's Candidate, School of Educational Science, Nantong University, Nantong 226000, Jiangsu, China.Email: 616636896@qq.com. 
W

ITH the rapid development of communication and information technology, China has been giving more expectations to education informatization, and set up higher requirements for the construction of educational resources (Chen, 2019). In 2012, The Ministry of Education of China (2016) clearly stipulated in the "Ten-Year Development Plan for Educational Informatization (2011-2020)", i.e., Build an educational cloud resource platform, bring hundreds of companies and 10,000 teachers and students together to develop excellent resources. In the same year, China held the first National Education Informatization TV and Telephone Working Conference, which clearly defined the purpose as "Three connections and two platforms" (Three connections mean schools connected with broadband network, classes connected with high-quality resource, and people can communicate in network learning space; The two platforms refer to the connection between public service platforms for educational resources and public service platforms for educational management and future development of Chinese education informatization (Liu, 2012). In June 2016, the "The 13th Five-Year Plan for Education Informatization" issued by the Ministry of Education clarified the focus of education informatization, which was to achieve the coordinated development of public service platforms and strengthen the ability of information service in teaching and management: Innovation of the construction and application model of "Day Day Up" platform, for serving classroom learning to supporting network-based extensive learning, improving the application level of education informatization, and deepening the integrated development of information technology and education (The Ministry of Education of China, 2016). On April 13, 2018, the Education Informatization 2.0 Act issued by the Ministry of Education proposed three transformation: (i) from dedicated resources to large resources; (ii) from improving students' application ability to information technology to technological literacy improvement; (iii) from application integration development to innovation integration development. By 2022, China proposed to reach the development goals of "three comprehensiveness, two height, one largeness". The "one largeness" herein refers exactly to the establishment of a large platform of "Internet + education" (The Ministry of Education of China, 2016). Under this background, students' learning cloud platforms have been springing up in China.

Tangquan Middle School in Nanjing, Jiangsu of China has been exploring an independent learning model for students based on the Internet environment. After years of practical accumulation, a unique network teaching platform model has been formed and achieved remarkable results. During this COVID-19 pandemic, our school actively responded to the call of "School is Out, But Class is On", and all students have adopted our self-developed network platform for self-study. To further discuss the effectiveness of the school's network platform, we proposed to obtain scientific evidence through a rigorously designed experimental study to evaluate its use.

\section{The Origin of the Experiment}

The education and learning cloud platform is the development of cloud computing in the field of education ( $\mathrm{Lv}$ et al., 2017). It is the basic structure of future education 
informatization, and develops along with technology. It includes all hardware computing resources. After virtualized these resources, they can provide a good platform for educational institutions, educators and students (Zhang \& Wu, 2010). The school selfdeveloped learning platform refers to a platform developed by three parts of schools, teachers, and parents together with a full consideration of both school and student conditions, so as to provide an equal and free learning environment (Lin, 2016).

Under the normal teaching conditions, no significant change occurred in many cases, i.e., e-learning platforms were only used as assistant means of teaching and supplementary means of learning, although the government advocated helping students learn through the Internet and issued a series of related policy documents (as mentioned in the introduction) to change the learning method and enhance the learning efficacy ( $\mathrm{Ni}$ et al., 2010). Therefore, it was difficult to see whether e-learning platforms were conducive to learning.

At the end of 2019, COVID-19 pandemic broke out. Due to its impact, teachers could not teach normally. Therefore, The Ministry of Education of China issued the document regarding "School is Out, but Class is On" in January 2020, which clearly stated that providing a variety of high-quality online teaching resources through coordinating and integrating national, local and school-related teaching resources that are available for selection (The Ministry of Education of China, 2020). In response to the call of the Ministry of Education, local government in Jiangsu had issued relevant countermeasures and built an "Internet + Education" model (Jiangsu Provincial People's Government, 2020), and in Zhejiang, the government issued "Guidelines for the comprehensive implementation of online teaching in elementary and middle schools during the postponed period of spring semester" (The Department of Education of Zhejiang Province, 2020), etc. It was proposed that all elementary and middle schools should implement online teaching by following the requirement of "School is Out, but Class is On", and encourage students to use the online learning platform during the pandemic. In order to better understand the use of the online platform, the Teaching and Research Office of Zhejiang Province organized a survey of middle and high school students that had a total of 558,982 participants. The survey showed that $96.0 \%$ of the students were involved in the online teaching activities organized by the school, and about $88.6 \%$ of them considered that they really wanted to participate in online courses and receive teacher's guidance (Teaching and Research Office of the Department of Education of Zhejiang Province, 2020). In addition, the Education Bureau of Zengcheng District of Guangzhou Province also conducted a survey on the online teaching for 155 schools. The study included 125,047 students, and 60\% of them expressed experienced a good learning of the platform (Southern Metropolis Daily, 2020).

In term of the online learning, other countries have already implemented earlier than China. Caleb Phillips in Boston, USA first suggested a private correspondence course through email, although the first electronic distance education could be tracked back to 1920 s that was performed through radio. The emergence of the Internet had caused a transformation of the distant education (Clark, 2020). The Clinton Administration of the USA announced in 1996 that it would broadly establish education on the 
Internet, they set the goal as before 2000, every classroom and every library should be connected to the Internet (Zhang \& Wang, 2008). Since then, studies started to observe the effectiveness of e-learning. Erik et al. (2008) found that as long as teachers had a better understanding of students, they could adapt online courses to the needs of students and maximize their success in online learning. Klaus (2003) believed that elearning platform was an integrated educational technology with e-learning. Through it, learners can participate in the construction of learning and can make progress in exploration and discussion in order to achieve a multi-angle and comprehensive understanding of knowledge (Garrison \& Terry, 1998).

In China, Lin (2019) pointed out that the online learning platform has the following benefits: (i) it provides a technical foundation for cooperative learning. (ii) it makes teaching more targeted on the contents. (iii) it reduces the peer pressure and improve student participation. Further, Lu (2020) believed that the combination of online learning platforms and classroom teaching had greatly stimulated students' learning initiative, effectively improved their ability to use words, and gradually realized the student-centered transformation of classroom teaching. Wan (2016) believed that the elearning platform developed by the school itself had a positive effect on Biology class. For example, in terms of the learning situation, it had reliable and accurate data; in terms of homework, it can be more targeted, reduce unified test papers, and carry out targeted personalized guidance; in terms of increasing interest, some students were more willing to complete homework on the Internet, they felt very cool.

Therefore, the online learning platforms have become the main tool for many schools to implement the reform of autonomous learning for students. Meanwhile, the school self-developed e-learning platforms achieved teacher-oriented teaching and student-oriented learning. In comparison, the public e-learning platforms lack of personalized property that only rely on the so-called standardized resources and tools.

In previous studies, factors like teacher guidance and the help of educational institutions were not ruled out. At the same time, no practical evidence shown whether the school self-developed learning platform was more conducive to learning. So this study observed the online learning platform developed by Tangquan Middle School in Nanjing, Jiangsu Province as the primary intervention variable, and discusses the following questions: (i) Can the use of modern educational technology promote learning? (ii) Is the school self-developed online learning platform more conducive to learning over the public-developed ones?

\section{Methods}

\section{Purpose}

As mentioned earlier, the use of e-learning platforms for teaching is a widespread phenomenon in elementary and middle school in China currently and is considered as an effective means to achieve student-centered learning. However, due to the difference in learning conditions in different schools in various regions, not all schools can use the same platform, i.e., some use public platforms, but some use independently developed 
by schools themselves. Under this background, the main purpose of this study was to investigate whether the e-learning platform developed by schools is conducive to student learning.

\section{Subjects}

We selected 7 th and 8 th graders ${ }^{\underline{I}}$ from two schools in Nanjing, Jiangsu Province as the subjects. Two hundred fifteen students from Tangquan Middle School were set as the experimental group and another 210 from another middle school were set as the control. In the experimental group, the school used its own educational cloud platform for teaching, while in the control group they used the public service platform of Jiangsu Education Resource as online teaching.

In order to better control the influence of students' preconditions and pre-test differences on the results; we first controlled variables such as the students' family background etc. After obtaining the pre-test results, we matched the data for the experimental and the control, and matched the participant sample according to the students' total scores of Chinese, mathematics, and English. After deleting the samples with missing testing, finally obtained 7th grade with the experimental group 98 samples and the control group 100 samples, 8th grade with the experimental group 110 samples and the control group 109 samples.

The two schools participating in the study were all public schools with good reputation. There are no significant differences between them in terms of teachers, students, and school hardware conditions.

\section{Primary Outcome}

The experimental test tool was a unified standardized test prepared by the Teacher Development Center of Pukou District, Nanjing. The staff who prepared the testing is rich in teaching experience, so it can guarantee the testing had good reliability and validity. The pre- and post-test of the three courses of Chinese, Mathematics and English were unified. These scores were the primary outcomes for evaluating the effectiveness of the self-developed online platform versus the public ones.

\section{Intervention}

In China, learning platforms are roughly divided into three categories. The first category is developed by the Ministry of Education or other local governments; the second category is developed by different companies; and the third category is developed by schools. Although the national and local governments and companies had put a lot of effort into the development and construction of the platforms, the first and second types are difficult to realize personalized learning for each student.

The intelligent cloud network learning platform developed by the school was the primary intervention of this study. It mainly included five parts: smart teaching, smart learning, smart growth, smart management, and smart training. These were different from the content of the online platform used in the control group. The obvious 
difference was that the core content provided by the smart teaching platform by Tangquan Middle School was the teaching resources developed by the school; the most important thing was the preparation of personalized teaching plans according to factors such as students' learning status and cognitive level. The control group used the Public Service Platform of Jiangsu Educational Resources, and the teaching was conducted as live broadcasting following the exam outline, it did not have any school self-developed resources.

During the COVID-19 pandemic period, Tangquan Middle School in Nanjing established a special working task. The school leaders and all teachers were carefully planned and arranged. Before the lesson, the room-teacher published the schedule on the teaching platform, other teacher issued the resource list and learning requirements, which guided students to preview and upload the preview results in time. After the class, the teacher reviewed and graded the homework, and did Q \& A with individual counseling on the platform in time (Dai \& Lin, 2020).

\section{Procedure}

This experiment was planned from the end of January 2020, officially started at the beginning of February and ended at the end of April 2020. At the planning stage, the two schools first identified the participating students, and through matching and comparison, to ensure that the basic situation were the same and no significant difference between them; Second, coordinated the teaching content and progress, and trained the teachers for both groups to ensure that the use of the online learning platform met the study requirements; At last, prepared the materials and determined the specific flow of the study.

From the beginning of February to the end of April 2020, it was the experimental implementation phase, which lasted 13 weeks. During this stage, the two schools taught according to the platforms they chose. Before and after the experiment, pre- and post-tests were taken. For the experimental group, the teachers can accurately take good control of the learning situation, and put different requirements for different students according to their learning ability to carry out personalized teaching.

\section{Results}

A total of 208 samples from the experimental group and 209 from the control group were valid for analysis. Prior to the study, in order to ensure the consistency of the learning level of the students in the two groups, a unified test was taken. The analysis of the test results is shown in Table $\mathbf{1 .}$

Before the study, all participating students from both schools used classroom to learn. For the three courses analyzed, independent sample $t$ test was performed using SPSS20.0. The $t$ value of the Mathematics was the smallest, 0.591 versus 0.314 , and the $t$ value of the Chinese was the largest, 0.806 versus 1.013 . There was no significant difference in the three courses between the two grades indicating both groups were comparable. 
After weeks learning, statistically significant differences were observed in all three courses for the scorings $(p<0.05)$. In this analysis, the test effect was expressed as a standardized mean difference (Cohen's d) as: 0.2-0.5 means small difference, 050.8 indicates medium difference, $>0.8$ means big difference. From this data, Chinese and English of the 7 th graders had a moderate effect size $(0.5 \leq \mathrm{d}<0.8)$, and Mathematics showed small effect amount $(0.2 \leq \mathrm{d}<0.5)$. For all three courses, the 8 th graders showed small effect size $(0.2 \leq \mathrm{d}<0.5)$. From the point of difference between the preand post-test scores of both groups, the difference of the post-test effect is much larger than that of the pre-test, indicating that the difference between the two groups is significantly increased (Table 2).

\section{Discussion}

\section{Can Modern Educational Technology Promote Learning?}

The integration of modern educational technology and education has always been a topic of great concern. Sivin-Kachala Jay (1994) observed the impact of modern educational technology on students' learning methods and academic performance pointed out that modern educational technology had a great influence on students' learning methods and achievements. The correct and reasonable use of educational technology in teaching can better stimulate students' interest; it can broaden their horizons, increase their knowledge, and cultivate their innovative ability. Zhao (2015) mentioned that the use of modern educational technology can improve the quality and effectiveness of information input, strengthen the authenticity of communication and feedback, and create more opportunities for researchers, a good opportunity to study the language learning process.

From these, it is easy to see that the combination of modern educational technology and education can effectively promote students' academic performance. At the same time, China has always maintained a supportive attitude towards the application of modern educational technology. In order to advocate it, the government had successively issued "The Ten-Year Development Plan for Educational Informatization (20112020)", "The 13th Five-Year Plan for Educational Informatization" and "The Educational Informatization 2.0 Act" and a series of policies (The Ministry of Education of China, 2012, 2016, 2018). Under the guidance of these series of documents, China had achieved the construction of education informatization 1.0, that is, the construction of "Three connections and two platforms". It was precisely because the national education informatization had achieved certain results that when the state issued the "School is Out, but Class is On" through the online e-learning platform" (The Ministry of Education of China, 2020).

Through our data, we believed that Internet education technology has been becoming a common way of changing school education, and it will change students' learning behavior and promote the innovation of education methods. This to large extent guarantee the performance of "School is Out, but Class is On" during the COVID19 pandemic. 


\begin{tabular}{|c|c|c|c|c|c|c|c|}
\hline Grade & Course & Group & Mean & SD & $t$ & $p$ & Cohen's d \\
\hline \multirow{8}{*}{ 7th } & \multirow{2}{*}{ Chinese } & Exp. $(n=89)$ & 75.051 & 5.844 & \multirow{2}{*}{0.806} & \multirow{2}{*}{0.421} & \multirow{2}{*}{0.115} \\
\hline & & Ctrl. $(n=100)$ & 74.145 & 9.499 & & & \\
\hline & \multirow{2}{*}{ Mathematics } & Exp. $(n=89)$ & 75.286 & 10.404 & \multirow{2}{*}{0.591} & \multirow{2}{*}{0.555} & \multirow{2}{*}{0.084} \\
\hline & & Ctrl. $(n=100)$ & 74.190 & 15.179 & & & \\
\hline & \multirow{2}{*}{ English } & Exp. $(n=89)$ & 74.296 & 10.831 & \multirow{2}{*}{0.783} & \multirow{2}{*}{0.435} & \multirow{2}{*}{0.111} \\
\hline & & Ctrl. $(n=100)$ & 73.095 & 10.761 & & & \\
\hline & \multirow{2}{*}{ Total } & Exp. $(n=89)$ & 224.633 & 17.856 & \multirow{2}{*}{1.067} & \multirow{2}{*}{0.287} & \multirow{2}{*}{0.152} \\
\hline & & Ctrl. $(n=100)$ & 221.430 & 23.890 & & & \\
\hline \multirow{8}{*}{ 8th } & \multirow{2}{*}{ Chinese } & Exp. $(n=89)$ & 75.186 & 8.104 & \multirow{2}{*}{1.013} & \multirow{2}{*}{0.312} & \multirow{2}{*}{0.137} \\
\hline & & Ctrl. $(n=100)$ & 73.862 & 11.032 & & & \\
\hline & \multirow{2}{*}{ Mathematics } & Exp. $(n=89)$ & 78.236 & 18.963 & \multirow{2}{*}{0.314} & \multirow{2}{*}{0.753} & \multirow{2}{*}{0.042} \\
\hline & & Ctrl. $(n=100)$ & 77.505 & 15.261 & & & \\
\hline & \multirow{2}{*}{ English } & Exp. $(n=89)$ & 77.359 & 10.195 & \multirow{2}{*}{0.880} & \multirow{2}{*}{0.380} & \multirow{2}{*}{0.119} \\
\hline & & Ctrl. $(n=100)$ & 75.922 & 13.720 & & & \\
\hline & \multirow{2}{*}{ Total } & Exp. $(n=89)$ & 230.782 & 29.340 & \multirow{2}{*}{0.899} & \multirow{2}{*}{0.370} & \multirow{2}{*}{0.122} \\
\hline & & Ctrl. $(n=100)$ & 227.289 & 28.138 & & & \\
\hline
\end{tabular}

\begin{tabular}{|c|c|c|c|c|c|c|c|}
\hline Grade & Course & Group & Mean & SD & $t$ & $p$ & Cohen's d \\
\hline \multirow{8}{*}{ 7th } & \multirow{2}{*}{ Chinese } & Exp. $(n=89)$ & 71.184 & 8.791 & \multirow{2}{*}{4.577} & \multirow{2}{*}{0.000} & \multirow{2}{*}{0.651} \\
\hline & & Ctrl. $(n=100)$ & 63.360 & 14.511 & & & \\
\hline & \multirow{2}{*}{ Mathematics } & Exp. $(n=89)$ & 70.398 & 13.014 & \multirow{2}{*}{3.416} & \multirow{2}{*}{0.001} & \multirow{2}{*}{0.486} \\
\hline & & Ctrl. $(n=100)$ & 63.180 & 16.480 & & & \\
\hline & \multirow{2}{*}{ English } & Exp. $(n=89)$ & 70.898 & 13.823 & \multirow{2}{*}{3.543} & \multirow{2}{*}{0.000} & \multirow{2}{*}{0.504} \\
\hline & & Ctrl. $(n=100)$ & 62.655 & 18.524 & & & \\
\hline & \multirow{2}{*}{ Total } & Exp. $(n=89)$ & 212.480 & 24.517 & \multirow{2}{*}{5.493} & \multirow{2}{*}{0.000} & \multirow{2}{*}{0.781} \\
\hline & & Ctrl. $(n=100)$ & 189.195 & 34.231 & & & \\
\hline \multirow{8}{*}{ 8th } & \multirow{2}{*}{ Chinese } & Exp. $(n=89)$ & 71.991 & 9.243 & \multirow{2}{*}{3.499} & \multirow{2}{*}{0.001} & \multirow{2}{*}{0.473} \\
\hline & & Ctrl. $(n=100)$ & 61.766 & 29.208 & & & \\
\hline & \multirow{2}{*}{ Mathematics } & Exp. $(n=89)$ & 74.473 & 27.489 & \multirow{2}{*}{2.159} & \multirow{2}{*}{0.032} & \multirow{2}{*}{0.292} \\
\hline & & Ctrl. $(n=100)$ & 66.583 & 26.575 & & & \\
\hline & \multirow{2}{*}{ English } & Exp. $(n=89)$ & 73.536 & 13.297 & \multirow{2}{*}{2.437} & \multirow{2}{*}{0.016} & \multirow{2}{*}{0.329} \\
\hline & & Ctrl. $(n=100)$ & 65.041 & 34.026 & & & \\
\hline & \multirow{2}{*}{ Total } & Exp. $(n=89)$ & 220.000 & 30.262 & \multirow{2}{*}{3.602} & \multirow{2}{*}{0.000} & \multirow{2}{*}{0.487} \\
\hline & & Ctrl. $(n=100)$ & 193.390 & 71.276 & & & \\
\hline
\end{tabular}




\section{Is the School Self-Developed Online Learning Platform More Conducive to Learning?}

Most domestic researches in China tend to study the adaptability of e-learning platforms, the construction and application strategies (Chen, 2019; Zhu, 2020), and rarely study the conducive effect on students' learning. Ye (2019) proposed a hybrid teaching based on cloud platforms. It was no longer centered on teachers and teaching materials. Teachers no longer had a single evaluation of learning, so they can understand students comprehensively and provide targeted guidance to promote the positive development of their learning. Liu (2020) showed that the emergence of a new learning approach such as an online platform had enhanced the diversity and flexibility of learning and improved the traditional classroom teaching, and constructed an independent learning environment for students. Outside of China, studies on whether online learning platforms conducive to students' learning were also carried out. Wang et al. (2002) studied the impact of learning effectiveness of giving advice to learners in the online learning environment, and concluded that giving learners guidance and advice at the right time could help improve the quality of learning. Zhou et al (2020) believed that students' selfdirected learning were conducive to the improvement of their academic performance. Yao et al. (2020) found that the effect of live teaching was better than the recorded teaching. Professor John Palfrey of Harvard Law School (2003) commented on the blog as one of the e-learning platforms: "Blog makes communication between teachers and students more convenient and effective, and achieves unprecedented effect in teaching and learning." Robinson (2008) studied the effectiveness of network platforms for learning at a technical level, and proposed that asynchronous communication technology could let learners have more time to learn critically and reflectively, which was more conducive to promoting the development of their higher-level thinking skills in the use, analysis, summarization and evaluation of knowledge. Therefore, it is easy to see that compared with the traditional classroom teaching mode, in which the teacher is the main body of the teaching activity and the student are in a passive state of receiving knowledge that ignores their characteristics of active cognition and the individual differences and needs (Ye, 2019), whereas e-learning platform is conducive to learning by providing students with more specific, suitable learning choices, and especially the school self-developed online learning platform is more conducive to learning than the public-developed ones.

\section{The Value and Deficiency of the Experiment}

In previous studies, the effectiveness of the online learning platform was established in normal teaching activities, and this study was conducted under the background of the COVID-19 pandemic, so it excluded the factors for teacher guidance and counseling in educational institutions, and its results have positive significance for the upcoming usage of online teaching platforms for future teaching.

However, we need to point out the limitations of this study. First, this study was that the sample size was not that big. Second, because the students study at home, 
the related variable could not be completely controlled. So in future studies, further improvement in the accuracy of the study design is necessary.

\section{Conclusion}

This study showed that (i) under the environment of "School is Out, but Class is On", it is feasible for students to learn independently, and (ii) the school self-developed elearning platform based on its personalized learning resources can significantly improve students' academic performance. Based on these, we suggest that schools and teachers should use online teaching platforms selectively. With the development of online teaching platforms, there are many online teaching platforms available on the market, so schools and teachers should choose them carefully.

In sum, the e-learning platform should be based on the school's learning situation and fully considered the differences in student learning have more significant impact on students' performance. Therefore, when schools and teachers do the online teaching, they should consider the actual situation of the school and choose the optimal one that is suitable most to students.

Note:

1. The 7th and 8th graders are the last two years of the middle school.

How to Cite: Dai, D., Xia, X. (2020) Whether the school self-developed e-learning platform is more conducive to learning during the COVID-19 pandemic? Best Evid Chin Edu, 5(1):569-580. Doi: 10.15354/bece.20.ar030.

\section{References}

Chen, T. (2019) Research on the adaptability of Ningxia education cloud platform teaching resources to elementary and middle school teaching. Yinchuan: Ningxia University.
Clark, J.T. (2020) Clinical Engineering Handbook (Second Edition), 410-415.

Dai, D.X., Lin G.F. (2020) Online home study plan for postponed 2020 spring semester during the COVID-19 epidemic: A case study of Tangquan middle school in 
Dai \& Xia. School Self-Developed e-Learning Platform During COVID-19 Pandemic.

Nanjing, Jiangsu Province, China. Best

Evid Chin Edu, 4(2):543-545.

Erik, W.B., Richard, E.F., \& Meredith, D.

(2008) An overview of evaluative instrumentation for virtual high schools. Am J

Dist Edu, 22(1):24-45.

Garrison, D.R., \& Terry, A. (2003) E-learning in the 21 century. Rout ledge Falmer.

Jiangsu Provincial People's Government. (2020) The province's education system "Suspends classes and does not stop schools" try to build an "Internet +Education" model.

John, P. (2003) The design of a synchronous virtual writing clinic. J Inform Sci Engineer, 19: 249- 265.

Lin, X. (2016) Development and application of smart learning platform and its effectiveness. China Infor Tech Edu, (20):100101.

Liu, L. (2020) Research on the satisfaction of self-study online English learning in middle schools and its teaching enlightenment. Shanghai Inter Stu Uni.

Liu, Y. (2012) Seize the opportunity to accelerate the creation of a new situation in education informatization: Speech at the national video and telephone conference on education informatization.

Lu, G. (2020) Based on the "learner-centered" concept to explore college English flipping class. English teacher, 20(02):8-11.

Lu, L., Shao, Y., Sun, H., Feng, C., Zhuang, S., et al. (2017) 2016-2017 Blue book of China's internet education industry. Peking University Press, O5-O1:156.

Mary, H.M. (1998) The urban university: An opportunity for renewal in hisher education. Innova Hisher Edu, 22(3).

Ni, X.D., Li, S.L., Cao, J., Ma, R. (2010) The advantages and disadvantages of network teaching platform in the application of course-assisted instruction. Mod Edu Sci, (08):70-71+31.

Robinson, C.C., Hullinger, H. (2008) New benchmarks in higher education: Student engagement in online learning. J Edu Bus, 84(2): 101-108.

Sivin, K.J. (1994) Report on the effectiveness of technology in schools, 1990-
1994 .Washington: Software Publishers Association.

Southern Metropolis Daily. (2020) How about the results of one week of "School is Out, but Class is On"? A survey of 550,000 middle school students in Zhejiang Province. Very few satisfied.

The department of Education of Zhejiang Province. (2020) What information is released in the survey report on online teaching of middle school students.

The department of Education of Zhejiang Province. (2020) Zhejiang Province postponed the spring semester of school to fully implement online education and teaching guidance.

The Ministry of Education of China. (2012) Ten-Year Development Plan for Educational Informatization (2011-2020).

The Ministry of Education of China. (2016) The Ministry of Education of China notice on printing and distributing the "Thirteenth Five-Year Plan for Educational Informatization".

The Ministry of Education of China. (2018) The Ministry of Education of China notice on printing and distributing the "Education Informatization 2.0 Act".

The Ministry of Education of China. (2020) The Ministry of Education of China: Use the internet platform, "School is Out, but Class is On".

Wan, S. (2016) Practice and strategy of personalized tutoring for middle school biology based on Yuantiku. Edu Inform Tech, (05):30-32.

Wang, Sutton. (2002) Effects of learner control with advisement on English-as-asecond- language students in a web-based learning environment. Inter J Instruct Medium, 29:317-324.

Yao, J.J., Rao, J.L., Jiang, T., \& Xiong, C,Q. (2020) What role should teachers play in online teaching during the COVID-19 pandemic? Evidence from China. Sci Insigt Edu Front, 5(2):517-524.

Ye, W. (2019) Research on the application of mixed teaching model based on E-online cloud platform: Taking the hand-painted POP course "Creative Heterosexual Post- 
Dai \& Xia. School Self-Developed e-Learning Platform During COVID-19 Pandemic.

er" as an example. Curriculum Edu Res, (40):42-43.

Zhang, Y., Wang, C. (2008) Where does online education go? Analysis of the status of online education at home and abroad. Today Keyuan, (18): 35 .

Zhang, Z., Wu, J. (2010) Research on cloud computing-based education information platform. China Dis Edu, (6): 66-69.

Zhao, Y. (2015). Recent developments in technology and language learning: A literature review and meta-analysis. Language Learn Higher Edu, 21(1):7-27.
Zhou., L., Li, C. (2020) Can student selfdirected learning improve their academic performance? Experimental evidence from the instruction of protocol-guided learning in china's elementary and middle schools. Sci Insigt Edu Front, 5(1):469480.

Zhu, G. (2020) Weihai smart education cloud platform network learning space construction and application research. Chin Edu Informat, (01): 68-71+77. 